\title{
An Empirical Study of Contrasting IoT with IT: Evidences of Differences Drawn from Japanese Experiences
}

\author{
Fumio Kodama \\ University of Tokyo, Tokyo, Japan \\ Email: kodama.fumio@emer.rcast.u-tokyo.ac.jp
}

How to cite this paper: Kodama, F. (2018) An Empirical Study of Contrasting IoT with IT: Evidences of Differences Drawn from Japanese Experiences. American Journal of Industrial and Business Management, 8, 27-58.

https://doi.org/10.4236/ajibm.2018.81003

Received: December 14, 2017

Accepted: January 9, 2018

Published: January 12, 2018

Copyright $\odot 2018$ by author and Scientific Research Publishing Inc. This work is licensed under the Creative Commons Attribution International License (CC BY 4.0).

http://creativecommons.org/licenses/by/4.0/

\begin{abstract}
By contrasting IoT (Internet of Things) with IT (Information Technology), various evidences of the difference between them are discovered by our empirical and case studies. For empirical evidence, a comparison is made between the personal computer as representing a case of IT and the automobiles as representing a case of the future IoT, since the self-driving of cars is discussed quite frequently nowadays. Based on their patenting behavior, the degree of modularization is measured, and effects of digitalization on modularization are found out to differ between PC and automobile industries. Similar modularity analysis is employed to sub-module suppliers, and they are found out to be integrative rather than modularly structured, because analogue technologies are essential at the level of sub-module supplying. Through our modularity analyses, it becomes clear that a digitalization brings about a modularization, and will eventually bring an IoT evolution. In order to illustrate the evolutionary process from digitalization to internetworking via modularization, we will investigate a chronology of the machine tool development in Japan ever since 1975. In order to illustrate the evolutionary process of becoming interconnected, we will make a study on a construction machinery manufacturer, i.e. how a manufacturer can go downstream into a service innovation. These case studies will show clearly that the process of upgrading of ITs into an IoT evolution is incremental by its nature and is additive in its essence, i.e. the value is added constantly. Therefore, an essential feature of IoT innovation is "creative accumulation" rather than "creative destruction." In this context, IoT innovation might be favoring some Japanese companies in terms of its components module suppliers as well as its system integrators. For an illustration of the Japanese competiveness of IoT module suppliers, two case studies of mobile sensors and of actuators are conducted. Through these case studies, the $\mathrm{M} \& \mathrm{~A}$ (merger and acquisition) is found to be
\end{abstract}


effective in terms of adaptive capacities of extending their core competences into changing fields of technology applications. This finding is far from the conventional wisdom about past Japanese strategies in which an extension was made by technological diversification rather than $M \&$ A. For the concept of creative accumulation to be implemented in the context of IoT evolution, a cautious strategic positioning rather than that of being different is necessary and effective. This argument is confirmed by case studies of Japanese strategies in terms of management of international $M \& A$, of going downstream into a service innovation, and of R \& D strategy of securing an independence from dominant suppliers. This is a good evidence that this IoT environment might come to favor again the emerging style of management by some Japanese companies. In order to summarize these evidence-findings, at the end of this paper, a comparison in perspectives on innovation is made between IT and IoT innovations. And it is discussed that IoT innovation is going beyond the Schumpeterian formulation of innovation.

\section{Keywords}

IoT, IT, Modularity, PC; Auto, HDD, Battery, Sensor, Actuator, AI

\section{Introduction}

It is widely held that a "new economy" is emerging since the 1990s, while the conventional wisdom about the innovation process has become obsolete. Since the "new economy" can be easily translated into a "digital economy," we have to think about what is new about the digital economy.

During the 1990s, indeed, Japanese consumer electronics companies have abruptly lost their international competitiveness, vis-à-vis those of the United States, Korea, Taiwan, and of China recently. I would argue that the techno-paradigm in the 1980s favored the Japanese style of management [1], but that the intrinsic nature of digital technologies did no longer favor Japanese companies in terms of managing innovations. In order to validate this argument, first of all, we will compare the personal computer as representing a case of IT (Information Technology) with the automobiles as representing a case of the future IoT (Internet of Things), since the self-driving of cars is discussed quite frequently nowadays. Based on their patenting behavior, the degree of modularization is measured, and we will find that effects of the digitalization on the modularization differ between the PC and automobile industries.

In order to investigate whether or not a digitalization is prevailing even at the sub-module level, we conducted similar modular analyses on the assembling of HDD (Hard Disk Drive) and of Battery for a hybrid engine, and we found that the modularization was not so much proceeding as at the level of module suppliers, since the analogue components of technology were conspicuous at the level of sub-module suppliers. And we observe that assemblers of these sub-module products are going to be integrative rather that modular structured. 
In a case of the batteries, car assemblers are trying to internalize manufacturing of these products in a long term. In terms of a future IoT system configuration, the results of analysis indicate that those sub-module units such as HDD and Batteries will be a direct component module to final systems more than to the final products like PC and automobile will be.

The IoT is defined as a global infrastructure for the information society, enabling advanced services by interconnecting (physical and virtual) things based on existing and evolving interoperable information and communication technologies. ${ }^{1}$ Through the forgoing analyses, we suggest that digitalization bring about modularization, and will eventually bring an IoT evolution. In other words, modularization, not digitalization, is a prerequisite to IoT evolution. In order to illustrate the evolutionary process from digitalization to internetworking via modularization, we will investigate a chronology of the machine tool development in Japan ever since 1975. In order to illustrate the evolutionary process of becoming interconnected, we will make a study on a construction machinery manufacturer, Komatsu, i.e. how the manufacturer can go downstream into a service innovation. This case study will show clearly that the process of upgrading into an IoT evolution is incremental by its nature and is additive in its essence, i.e. the value is added constantly.

Based on this case study, I would argue, the essential feature of IoT innovation is the "creative accumulation" rather than the creative destruction. Therefore, the IoT innovation might be favoring some Japanese companies in terms of components module suppliers as well as system integrators. For the illustration of the Japanese competiveness of IoT module suppliers, two case studies of mobile sensors (which detected the use of defeat device in the VW scandal) and of actuators (a world-wide market domination of tiny spindle motors) are conducted. Through these case studies, we find that M \& As' (merger and acquisition) are effective in terms of adaptive capacities of extending their core competences into changing fields of technology applications.

Everyone agrees that AI (Artificial Intelligence) technologies will definitely compose a critical part in the coming IoT innovation. Although the research on AI technologies had been conducted all over the world in several decades since 1960s, however, the realization of AI technologies occurred much less occurred than we had expected. This situation is even more valid when it comes to the commercialization of AI technologies. In order to find out evidences of the Japanese competitiveness in AI technologies, in this context, I will describe the development of a Japanese word processor which solved the linguistic problems of a complicated language and its commercialization process. Indeed, the way in which they solved problems related to cultural characteristics, has diffused throughout the countries whose language is based on ideogram rather than phonogram, and was helpful in the office automation in these countries.

Since the process of IoT evolution is characterized as incremental and additive, a cautious positioning is an important strategy for both the system integra${ }^{1}$ http://www.itu.int/ITU-T/recommendations/rec.aspx?rec=y.2060 
tors and the module suppliers in IoT evolution. We will illustrate a cautious strategic positioning rather than the positioning of being different [2], was effective, in terms of management of international $M \& A$, of going downstream into a service innovation, and of R \& D strategy of securing an independence from dominant suppliers. Based on findings made in these case studies, we will discuss how the concept of creative accumulation can be implemented in quite a new environment, and this environment might come to favor again the emerging style of management by some Japanese companies. In order to summarize these evidence-findings, at the end of this paper, we will make a comparison in perspectives on innovation between IT and IoT innovations. And I will argue that the IoT innovation is going beyond the Schumpeterian formulation of innovation.

\section{Comparison in Modularization between PC and Auto Assemblers}

As is well known, dramatic changes occurred in the computer industry. Around 1980 , the computer industry was composed of vertically integrated firms. Hence, the industry had an extremely vertically integrated structure. Around 1995, however, the industry shifted to a horizontal competition. Drastic changes in the industrial structure occurred when computer manufacturers began to obtain various components from outside and to combine them [3].

Baldwin and Clark argued, the personal computer (PC) industry that has grown up around the modularity, developed entirely new kinds of computer systems that have taken away share from the mainframe market [4]. They assert: technical managers at the assemblers expect that the newly strengthened module suppliers are to take on most of the design responsibility. Therefore, we can assume that the technological responsibility and leadership has shifted from the assembler to the components supplier. However, how much is this argument valid across the industry?

In order to test this argument, we will compare the personal computer as representing a case of IT (Information Technology) with the automobiles as representing a case of the future IoT (Internet of Things), since many of the auto companies are going in a direction towards the self-driving.

\subsection{Modularity Analysis of PC Industry}

Based on the observation described above, we can measure how much the modularization had been developed [5]. We can hypothesize that this shift towards the modularization should be reflected in patenting activities ${ }^{2}$. By taking modular innovations of PCs into account, we selected the following four categories of components: CPUs, memory, disks, and display. Then, we selected an appropriate combination of several key words to represent each of the four component

${ }^{2}$ For our measurement, we used a patent database called PATORIS (Patent Online Information System), a systematic online search system of patent information in Japan. The information in this database goes back to 1955 and contains about 40 million entries, as of around 2000. 
areas. Our key words search was made on data of patent title and summary information about the patent ${ }^{3}$. Then, we could measure the percentage of patent applications filed by PC assemblers in each of component areas. The changes from 1986 to 1997 are shown in Figure 1.

As seen in the figure, the assemblers' shares in all the component areas stayed quite high with some fluctuations during the 1980s. Around 1990, however, all of these shares suddenly began falling and continued to drop consistently thereafter. This indicates, first of all, that the responsibility and leadership in technological development shifted from the assemblers to the individual component module providers. Therefore, we can ascertain that the modularization has drastically progressed in the PC during the 1990s. We can also ascertain that the modularization has driven the change in industrial structure of computer industry from a vertical to a horizontal structure [3].

\subsection{Modularity Analysis of Automotive Industry}

We will go to an analysis of the automobile as representing a case of the future IoT (Internet of Things). In the automotive industry, it was once argued that the modularization was not yet so visible during the 1980s. This was because the focus of competition was on the product integrity, especially on the internal integrity, e.g., how well the parts fit, how components match and work well together, and whether the layout achieves maximum space efficiency [6]. When we entered into the 1990s, however, big assemblers in automotive manufacturing have been moving away from the tightly centralized design.

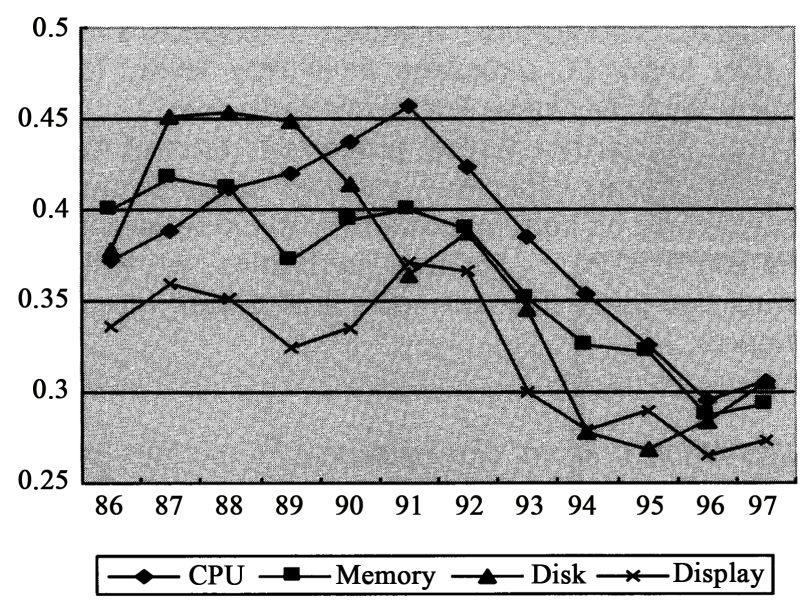

Figure 1. Changes in shares of PC assemblers in patent applications. Source: Kodama, 2004 .

${ }^{3}$ We compiled the patent applications in every year from 1986 to 1997. Pertaining to CPUs, for example, 695 and 1595 patents are compiled in 1986 and 1997, respectively. In other areas of components, 2013 and 5316 memory-related patents, 111 and 5316 disks-related patents, 1415 and 5597 display-related patents were compiled for 1986 and 1997, respectively. Since our attempt is to measure the progression of modularization by means of the shift in patent application from the assembler to the supplier, we have to ascertain who filed the patent, assemblers or suppliers. For this purpose, 10 companies are identified as the PC assemblers in Japan: Sony, IBM, NEC, Matsushita, Fujitsu, Hitachi, Sharp, Mitsubishi Electric, Toshiba, and Epson. 
Automotive designers and engineers are now looking for ways to parcel out the design of their complex electromechanical system [4]. Therefore, we conducted a similar patent analysis as we did in the PC. For our study of the automotive industry, as a representation of the IoT innovation, our patent counting is applied to the following four categories of control systems: engine control, chassis control, safety control, and communication control systems. ${ }^{4}$ This set of categories is, as you may be aware, different substantially from those categories used for analyzing the structural modularity of an automobile (engine, chassis, interior, and body structure). We selected an appropriate combination of several key words to represent each of the four controls systems. As a result, we compiled the patent applications in every year from 1976 to 1998. For each control system, we measured the ratio of automotive assemblers in the patent application, as shown in Figure 2.

As seen clearly in the figure, the shares of automotive assemblers did not decrease so much in the 1980s and some of them increased in such control systems as the chassis and the safety control. In the 1990s, however, these shares abruptly began falling in the chassis control, safety control, and communication control systems. In other words, the modularization proceeded rapidly when the automotive industry entered the 1990s. However, there is one obvious exception in this trend of modularization. The exception is in the engine control system. As can be seen in the figure, the share of automotive assemblers in the engine control system increased in the 1990s; that is, the modularization did not proceed.

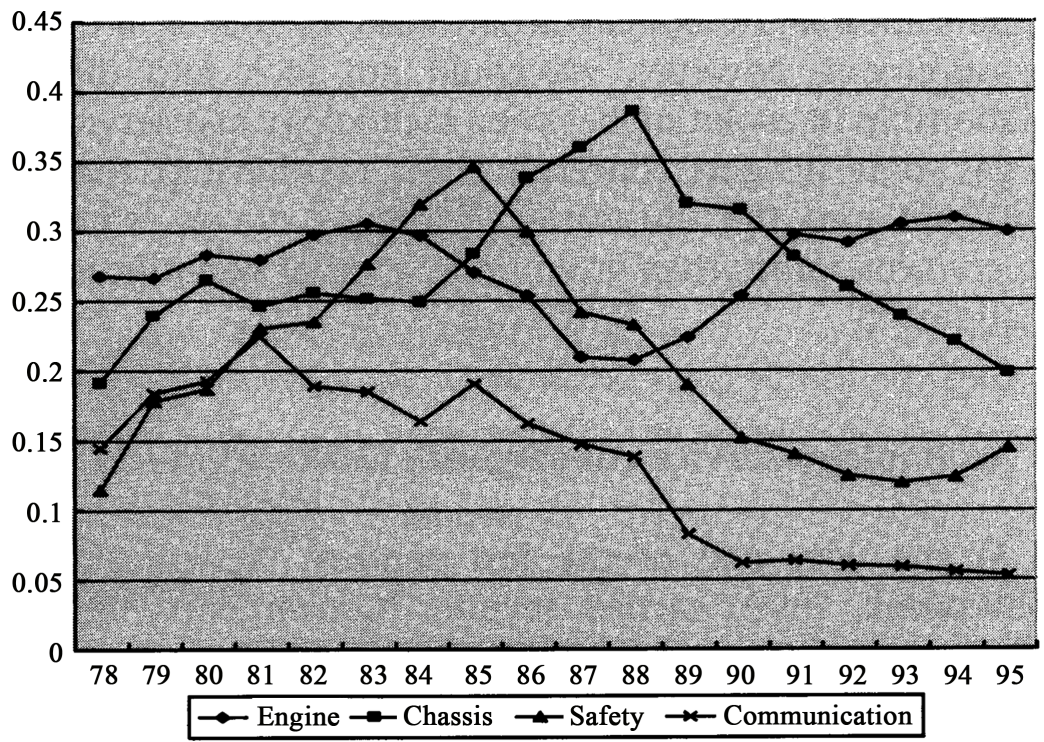

Figure 2. Changes in shares of automotive assemblers in patent applications. Source: Kodama, 2004.

${ }^{4}$ More specifically, engine control system includes that electronic control for fuel injection, vaporizer, and muffler. Chassis control system includes those electronic controls for automatic transmission, suspension, antilock braking system, traction, four-wheel drive, and power steering. Safety control system includes such items as air bag, back sonar, automatic wiper, automatic air conditioner, cruise control, and keyless entry system. Communication control system includes such items as car navigation system, display meter, and optical communications system. 
This is different from the case of PC in which the modularization proceeded in all the component modules. Now, we are interested in analyzing why the modularization in the engine control system did not proceed in the 1990s, while the modularization in other automotive control systems is visible.

\subsection{Digitalization and Modularization}

Why did the assemblers' share of patenting decrease continuously since 1990 in all the control systems except the engine control? Why did the modularization of these control systems proceed in one way direction?

We can postulate that the differences in modularization have something to do with the differences in digitalization of the automotive components. The technological base of the digitalization of automobile's control systems lies in the three elements: a sensor, an actuator, and an electronic control unit (ECU) that is inserted between sensor and actuator. In other words, the sensor detects the information about the change occurring outside the system, and transmits it to the ECU. The actuator manipulates the system operation based on the command instruction received from the ECU. Therefore, the pivotal component of the electronization of automobiles is the ECU, which is equivalent to the computer by itself. As of 1995, indeed, approximately ten ECUs were mounted in a small car for the electronics-controlled automatic transmission, the power steering, the powered windows, the angle adjustment of mirrors, and the control of the air conditioner. The bigger cars carried about 20 ECUs, and the high class cars did more than 30 ECUs $^{5}$.

Thus, we tried to measure the degree of digitalization in terms of the relative value of ECUs built in each control system. Specifically, the production value of ECUs for each control system is divided by the total value of automotive parts production. In other words, the relative economic weight of ECUs built in each control system is used for the index of digitalization. Results of this measurement show that digitization in engine control systems has not advanced; or rather there is a declining trend, while digitalization has advanced drastically in the other three control systems, as seen in Figure 3.

Based on this comparative measurement of modularization in PCs and automobiles, we can learn something about the relationship between the degree of modularization and the penetration of digital technologies. The deeper the penetration of digital technologies is, the further progressed is the modularization. Therefore, it is now clear that introduction of digital technologies makes the modularization possible and drives the industry towards horizontal competition. In an industry where not all the technologies are digital, as is found in the automobile industry, the technological leadership of assemblers remains strong as it was before.

So far we have been interested in the comparison between PC and automobile industries. However, the recent argument on a "self-driving car" indicates that

${ }^{5}$ As of 2006, approximately 50 - 60 ECUs are mounted on an average car (Nikkei, 2006/3/27). 


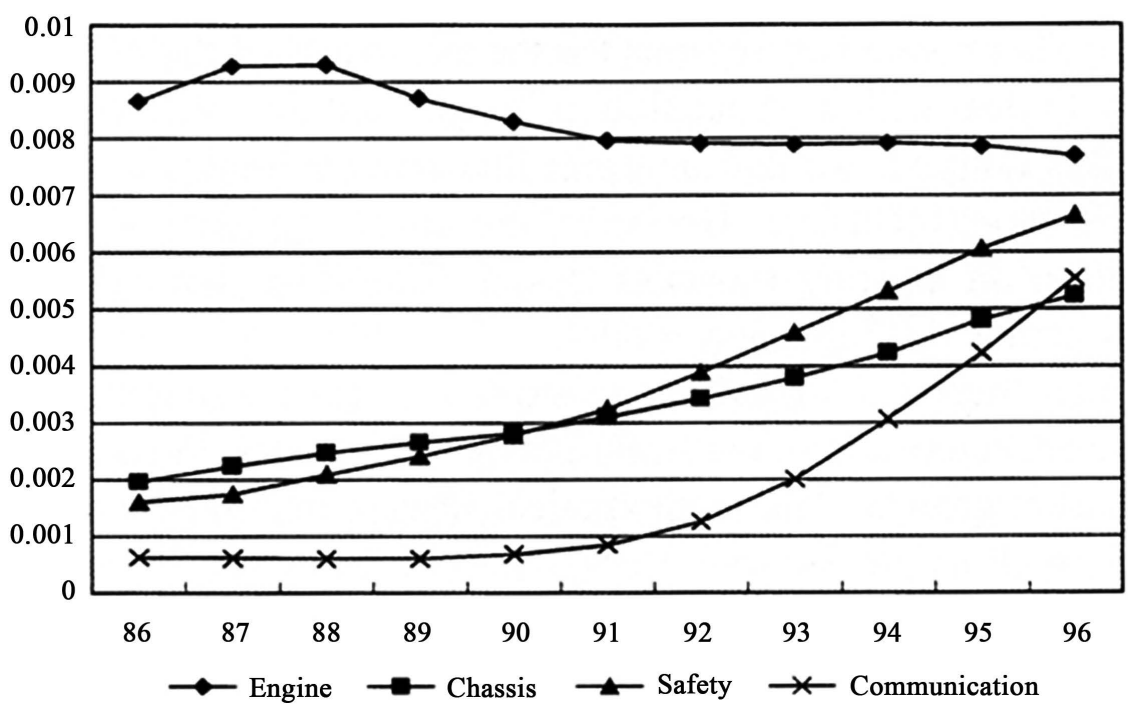

Figure 3. The weight of ECU in each category of automobile control systems. Source: Kodama, 2004.

the integration of these two industries is more important than the comparison between them. And it is obvious that the digitalization of major component modules will be integrated into a total transport system, i.e. towards an IoT (Internet of Things) innovation. This indicates that digitalization brings about modularization, and it will further bring about an IoT evolution. In other words, the modularization, not the digitalization, is a prerequisite to a future IoT evolution.

\section{Modularity Analysis on the Sub-Module Supplying}

One of the features of modular structure is hierarchy. Therefore, we are now interested whether similar trends can be observed in the relationship between first-tier module providers and second-tier component suppliers. We do not yet know whether this similar trend is conspicuous even in the different types of technologies, i.e. in the area where analogue types of technologies are still dominant.

\subsection{Sub-Module in PCs: Analysis on HDD Assembling}

Among the four categories (CPUs, memory, disks, and display) in the analysis described above, the category of disks might involve an analogue technology which is necessary for bringing the physical movement into action. Taking the HDD (Hard Disc Drive) as a prototypical example, therefore, we will study on this relationship using the same analysis on patenting activities. Our analysis is based on the U.S. patent database during 1986-2004, which is provided by the US Patent and Trademark Office. The seven HDD assemblers are identified: Seagate; Maxtor; Western Digital; IBM; Hitachi; Toshiba; and Fujitsu. Based on the IPC (International Patent Classification), all the patent applications are classified as one of the following five product categories: magnetic disks; heads; disk head mechanism; signal processing; and, vertical memory. 
The results of measurement in the HDD assemblers' share are shown in Figure 4. As can be seen clearly, the HDD assemblers' shares have increased consistently in all the five areas of HDD components, without exceptions. As seen in the figure, the results of our measurement are almost opposite to those of PC assemblers, indicating that its industrial structure is integrative rather than modularly structured.

It is to be noted that the steady increase in leadership of the HDD assemblers did occur in spite of the radical technological shifts in the component technologies of the HDD during the observation period: in the category of magnetic disks, the emergence of anti-ferromagnetic-coupled disk which improved the signal noise characteristics; the shift in heads technology from the ferrite heads, thin film heads and the magnetic resistive heads; and, the shift occurred in the head disk mechanism from the contact start stop system to the ramped loading system, and etc. Indeed, the total number of patent applications (HDD assemblers plus the module components suppliers) did increase drastically. This means that some assemblers are following a vertical integration model, while some assemblers are following a horizontal coordination model in which some components are procured from outside, with the design leadership kept at assemblers.

Based on the two analyses described above, we can conclude that the modularization in PC assembling has progressed drastically and the outsourcing of module suppling did also proceed substantially. At the level of component supplying to module providers, however, the trends of technological leadership (measured by the ratios of providers' patent applications) are found out to be almost opposite, for example, in the relationship between HDD providers and their components suppliers. When it comes to the strategy of vertical integration in HDD assemblers, we finds a difference in their strategies among the seven assemblers, as shown in Table 1. In this table, a comparison is made about the "make or buy" decision of subcomponents among HDD assemblers.

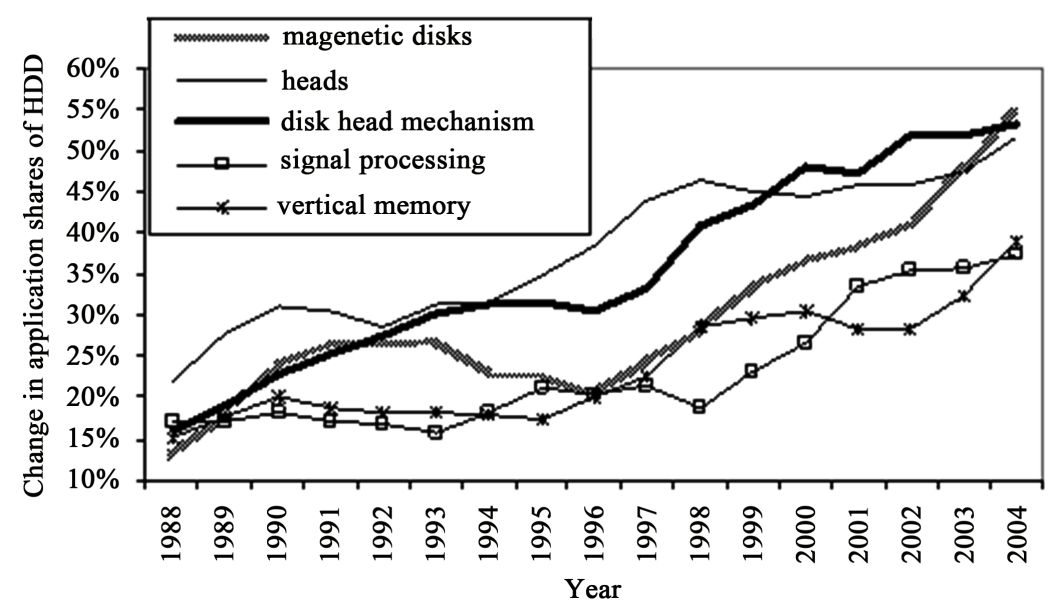

Figure 4. The change in application shares of HDD assemblers by product categories. Source: Kudo, T. (2008): Master dissertation at graduate MOT school, Shibaura Institute of Technology. 
Table 1. The make-or-buy decisions by HDD manufacturers.

\begin{tabular}{ccccccc}
\hline Firm & Types & Disk & Head & Pre-amp & Lead-channel & Motor \\
\hline Seagate & 3.5 inch & $\bigcirc$ & $\bigcirc$ & $\times$ & $\times$ & $\times$ \\
Maxtor & 3.5 inch & $\bigcirc$ & $\bigcirc$ & $\times$ & $\times$ & $\times$ \\
WD & 3.5 inch & $\times$ & $\bigcirc$ & $\times$ & $\times$ & $\times$ \\
Hitachi & All & $\bigcirc$ & $\bigcirc$ & $\bigcirc$ & $\bigcirc$ & $\bigcirc$ \\
Toshiba & 2.5 inch less & $\times$ & $\times$ & $\times$ & $\times$ & $\times$ \\
Fujitsu & $3.5 \mathrm{E}$ and 2.5 & $\bigcirc$ & $\triangle$ & $\times$ & $\times$ & $\times$ \\
\hline
\end{tabular}

(O) vertical integration; $\times$ : outsourcing. Source: Kudo, T. (2008): Master dissertation at graduate MOT school, Shibaura Institute of Technology.

As seen in the table, there exist only two companies, Seagate and Hitachi, who are rather choosing a vertical integration in their manufacturing, while Seagate concentrates on the 3.5 inch disk and Hitachi is producing all sizes of disks. This reminds us the following past analysis on the Japanese strategy in electronics industry: compared with the US startups, Japanese firms are taking advantages of being vertically integrated. This argument is, however, no longer valid since these two companies differ in the profit-making: Seagate is most profitable, while Hitachi who purchased the HDD business from IBM is not making profits. It is also to be noted that Hitachi is the only HDD provider who is manufacturing even the spindlemotor, among these seven providers we studied. As is well known, almost all the HDD providers are outsourcing their components to a specific supplier, Nidec Corporation of Japan, which will be analyzed further in the next section. And Hitachi, indeed, withdrew later from the business of manufacturing the HDD in $2012 .^{6}$

In summary, the trends towards modularization are not simple, and are different between PC assembling and component module supplying, some of which are based on analogue technologies. What is important is, therefore, not a vertical integration for itself, but the integrative capacity of digital and analogue component modules and the manufacturing capacity to implement the optimal level of vertical integration.

\subsection{Sub-Module in Autos: Analysis on Battery Assembling for Hybrid Engines}

Apart from the non-digital nature of engine control module described above, the upward reflection in engine control system during 1989-1995 has also something to do with the development of hybrid engine system. As is well known, a first hybrid car called as "Prius" was introduced into market by Toyota in December 1997. Therefore, we made a follow-up study, which analyzed the trends during 1991-2004, as seen in Figure 5.

${ }^{6}$ HGST (Hitachi Global Storage Technology Inc.) was created in 2002 by purchasing the HDD business from IBM, and it was sold out in 2012 to Western Digital (WD). 


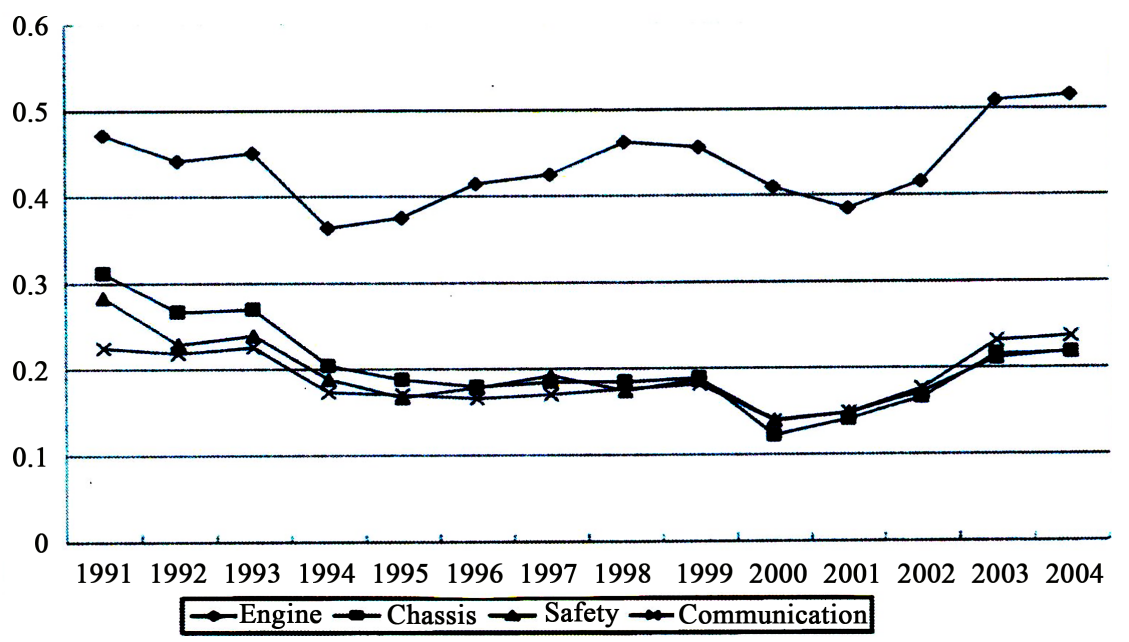

Figure 5. The change in assembler's share in the control systems (1991-2004). Sources: Fujita, Y. (2008), Master Dissertation at MOT graduate school in Shibaura Institute of Technology, Tokyo.

As can be seen in the figure, the assembler's share in engine control rose up steeply again in 1994, and peaked in 1998. And, the second generation of Prius was brought into market on September 2003. The share did rise sharply again in 2002. This means that Toyota geared up the internal development of major components such as the battery. And, indeed, the size of battery was reduced by $50 \%$ and its weight by $40 \%$, compared with the first Prius' battery.

Since a hybrid car appeared in market, indeed, Toyota gradually internalized the development of major component technologies of hybrid engine such as the batteries. However, in its early stage, Toyota had to rely on the supply of batteries from Panasonic Co. Therefore, we investigated on the patenting behavior of Toyota and of Panasonic, as far as the patent classification of Battery (International Patent Classification of H01M) is concerned. We are interested in the process through which Toyota acquired the battery technology through their procurement from and joint research with Panasonic. This dynamic process can be measured by their patenting activities: single application by Panasonic; single application by Toyota: Panasonic-Toyota's joint applications (Joint application with Toyota as the principal applicant, and those with Panasonic as the principal applicant; and, applications by joint venture (Panasonic EV energy Co.)), as shown in Figure 6. As clearly seen in a figure, the number of single application by Toyota finally caught up with that by Panasonic in 2005 .

It is to be noted that the number of applications by Panasonic EV Energy Co. peaked in 2002, while joint applications with Toyota as the principal applicant did only saturate in growth around 2004. Therefore, we can generalize: whenever a drastic change occurs in the system configuration, a system integrator outsources a key component which becomes necessary for the new configuration, especially if this component is based on analogue and/or chemical technologies. Through a joint research with the component supplier, a system integrator soon or later begins to internalize its manufacturing. Indeed, it took almost ten years 

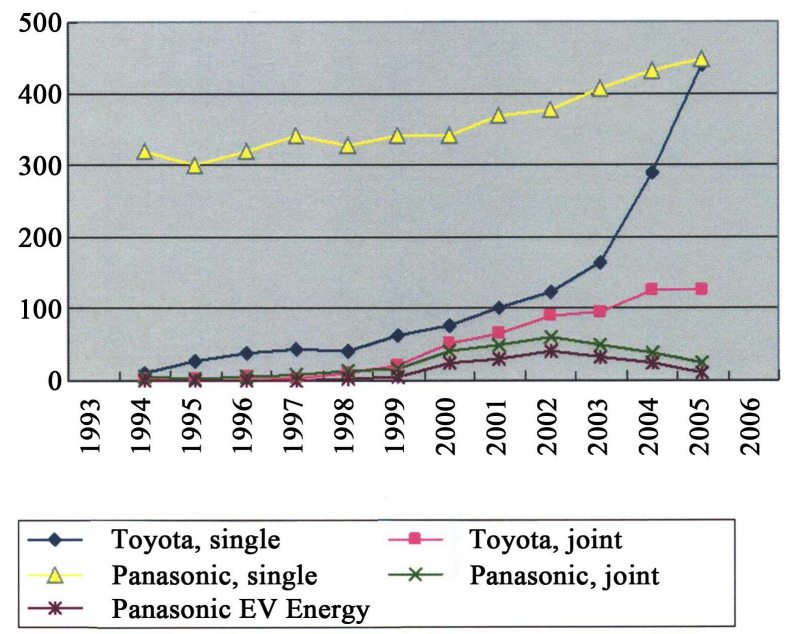

Figure 6. Patent application in battery by applicants. Source: Hayashi, M. (2008): Master Dissertation at MOT graduate school in Shibaura Institute of Technology, Tokyo.

for Toyota to absorb a battery technology from a module supplier, i.e. Panasonic.

In summary, what is important is, an assembler's absorptive capacity of the component technologies which become necessary because of the emergence of a new configuration brought about by the assembler's design change. It is an ability of learning pivotal technologies for the new configuration from suppliers if the component technology is basically analogue or chemical like the battery. It is also the capacity of internalizing and of improving this technology so that the total system efficiency can be drastically enhanced. Building on their experiences of joint efforts, Panasonic is now a world largest supplier of car-batteries. For a joint development of the batteries for EVs (electric vehicles), Toyota and Panasonic are in their final stage of negotiation and also of a standard setting of batteries for EV, in which Honda, Mazda, and Daihatsu will be involved (Nikkei, 2017/12/13).

\subsection{Implications on IoT Evolution}

In a future configuration of IoT system, the current assemblers such as PC and Auto manufacturers will no longer be critical component suppliers. You can easily imagine this situation, since the future IoT might be a more direct integration of the physical world into computer-based systems ${ }^{7}$. This implies that a PC will not be an independent module for a smart grid distribution system involving the memory as a critical module, nor is the automobile that for an intelligent transportation system involving the battery as a critical module.

In addition, our analyses indicate that a digitalization bring about a modularization, and it will eventually bring about an IoT evolution, but the process will not be a straight progression, since the analogue element of technology will remain as the basis of critical module suppliers. In order to complete this process,

${ }^{7}$ http://www.itu.int/ITU-T/recommendations/rec.aspx?rec=y.2060 
we will need a totally new line-up of system configuration, otherwise, it will be not possible for us to reach a new architecture for the future IoT system. In other words, we might have to dissolve an established system configuration and to start in re-editing a new configuration most appropriate to the IoT system. In short, a fusion of digital technologies with analogue ones is an absolute necessity [1].

\section{Emerging Patterns of the IoT Evolution}

IoT is defined as a global infrastructure for the information society, enabling advanced services by interconnecting (physical and virtual) things based on existing and evolving interoperable information and communication technologies. ${ }^{8}$ The evolutionary process from the modularization to the internetworking is best illustrated by an investigation on the chronology of machine tool development in Japan ever since 1975. The evolutionary process from the invention of a single module technology to becoming interconnected is best illustrated by a study on a construction machinery manufacturer, Komatsu, i.e. how the manufacturer can make a service innovation.

\subsection{Evolution from Modularization to IoT: A Study of Machine Tools}

The numerically controlled (NC) machine tools have a long history. However, the NC machine tools controlled by personal computers (PC) were only recently realized, because NC and PC evolved independently through their own evolutionary paths [7]. The two systems reached different modular architectural structures through their own evolutionary paths: the PC reached "open" architecture, while the NC reached "closed" architecture. Therefore, it is difficult for these two systems to be integrated, although both are modular structures. Indeed, the PC controlled NC (PC-NC) was realized only after the NC system became an open architecture system in which three functions, display, calculation, and drive, were modularized and worked independently without any interferences. Ever since 1975 when a microprocessor unit (MPU) was first incorporated into NC equipment architecture, various searches have been made for appropriate module partition to accompany the latest advances in elemental technologies. As a result, NC architecture has achieved three different module partitions, as shown in Figure 7.

The integration of a PC function into the display unit of an NC, moreover, realized the NC system with flexible and enhanced PC functions such as database and networking. The database function, for example, enabled an NC operator to manage tool files; customize operation screens; and freely build human interfaces. The PC's networking function could also be used to operate NCs in a factory from a remote location via internet. The combination of PC's abundant information processing functions with control functions heralded innovations

${ }^{8}$ http://www.itu.int/ITU-T/recommendations/rec.aspx?rec=y.2060 


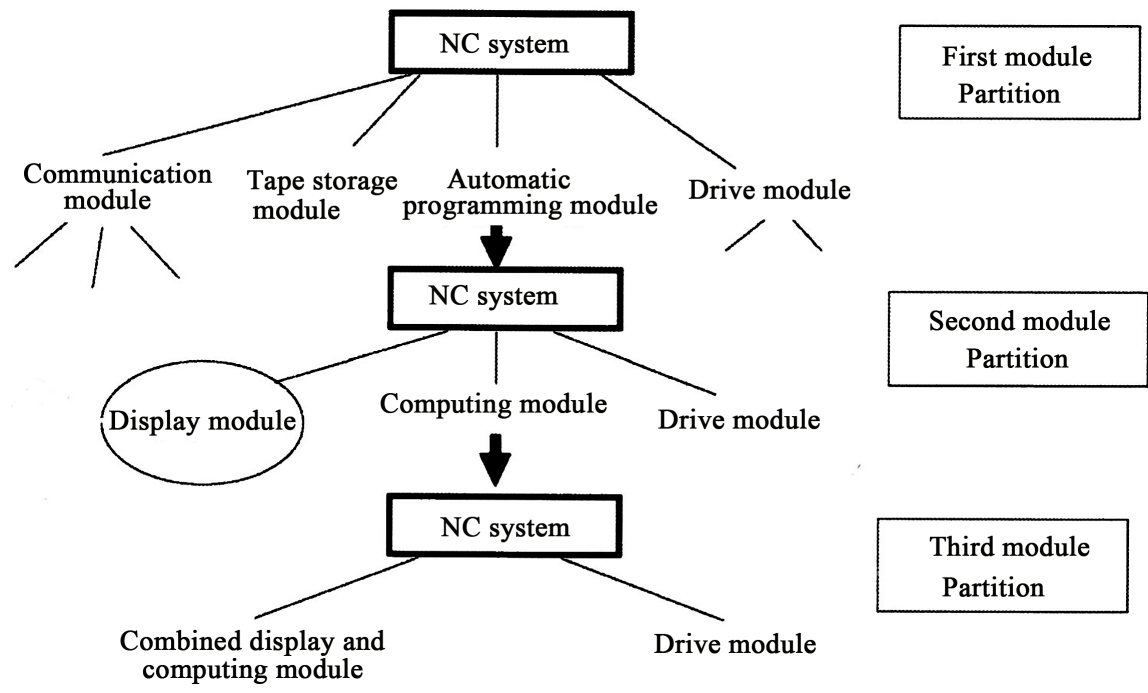

Figure 7. Changes in module partition of NC machine tool. Source: Shibata (2009).

that turned an NC equipment into a product with diverse uses (customer value) at a more technologically-advanced level.

In this context, Mori Seiki Co., a leading Japanese machine tool manufacturer and user of NC controllers, developed their own PC-NC by inserting consumer PCs to the display module of their NC system. Development began in 1997, and the MAPPS (Mori Advanced Programming Production System) was released in 2000. Mori Seiki has now completed the improved version, MAPPS III, and is using it in all its models. This has enabled Mori Seiki to produce their own common specifications for operation and display methods independently of NC controllers' manufacturers, as depicted in Figure 8.

As an IoT innovation is deepening in contents and widening in scope, several Japanese machine tool suppliers are initiating their collaboration with IT giants both in the United States and in Japan. In the development of a security system, DMG-MORI SEIKI, a merger of Mori Seiki with the German DMG (Gildenmeister Aktien Gesellschaft), is collaborating with Microsoft of Japan. In developing an equipment to protect factory facilities from cyber-attacks, Yamazaki Mazak Corporation is conducting a joint project with US Cisco Systems, Inc. Fanuc is developing a unique system with Cisco Systems to combine IoT with AI. And Okuma Corporation is collaborating with Hitachi in enhancing the efficiency of factory by using IoT (Nikkei, 20017/07/24).

The machine tool manufacturers' trend of transforming themselves into IoT system integrators has been vividly demonstrated in an industry fair of "Mehatronics Japan" held at Nagoya of Japan in the mid-October of 2017. The world largest DMG-MORI demonstrated a production management system called "DMG MORI messenger," a software which makes the online monitoring of all the machines' operating conditions within a factory. In addition to IoT functions, DMG-MORI is aiming at a production system integrator. Indeed, they are providing customers with a DMQP (DMG-Mori Qualified Products) program, 
Going beyond integration of PC with NC

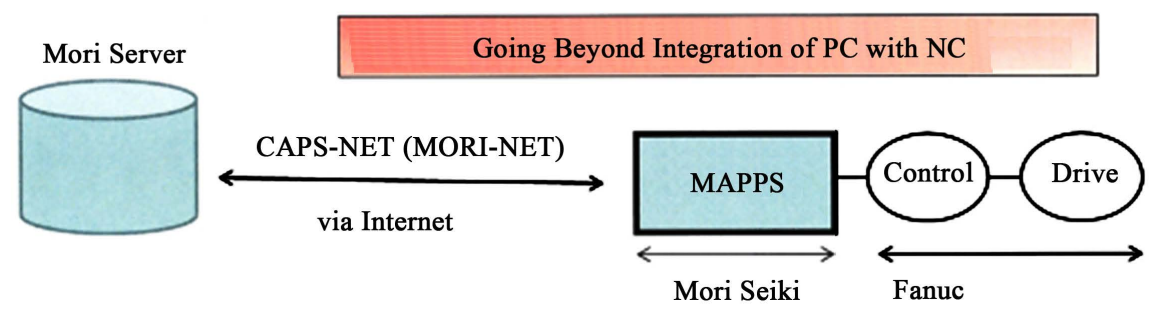

Figure 8. Going beyond integration of PC with NC. Source: Shibata (2016): "IoT and Innovation (in Japanese)," Newton, Vol. 27, 4-13.

which is designed to certify peripherals that meet DMG MORI standards in quality, performance and maintainability. They are going to provide with a comprehensive support, from proposal to delivery and maintenance, and for high-quality peripherals that offer superior performance and maintainability. The president Masahiko Mori stresses that they can accommodate all the differences in world standards, since the 50 percent of their total sales are in these three countries: Japan, Germany and the United States.

By a use of AI technologies for preventive maintenance, Yamazaki Mazak built a world most advanced un-maned factory of parts manufacturing, i-smart factory, by investing ten billion yen. Okuma developed its "OSP-AI" which can be mounted to a CNC (computerized numerical controller), in order to detect any abnormalities of the ball-screws that drive the main spindle. JTEKT Corporation has brought into market their JTEKT-Signal Hop, equipment which can easily monitor the operating conditions of all the machines in a factory, irrespective of any age of machines made by any manufacturer (Nikkei, 2017/11/16).

\subsection{Process of Becoming Interconnected: A Study on Construction Machinery}

With regard to the IoT (Internet of thing), "thing" is an object of the physical world (physical things) or the information world (virtual things), which is capable of being identified and integrated into communication networks. ${ }^{9}$ Therefore, an important characterization of IoT is the network connectivity that enable these connected objects to collect and exchange data.

How can physical and virtual things be interconnected? The process of interconnecting can be best illustrated by a recent case of a Japanese construction machinery supplier, Komatsu Co. Komatsu is the first company which introduced these disruptive technologies such as RFID (Radio Frequency Identification) and GPS (Global Positioning System) for constructing building lots, and now is a market leader in the construction businesses (Nikkei Business, 2007). As shown in Figure 9, RFID sensors are inserted inside their machines operating all over the world and all the data about their operating conditions are sent to

${ }^{9}$ http://www.itu.int/ITU-T/recommendations/rec.aspx?rec=y.2060 


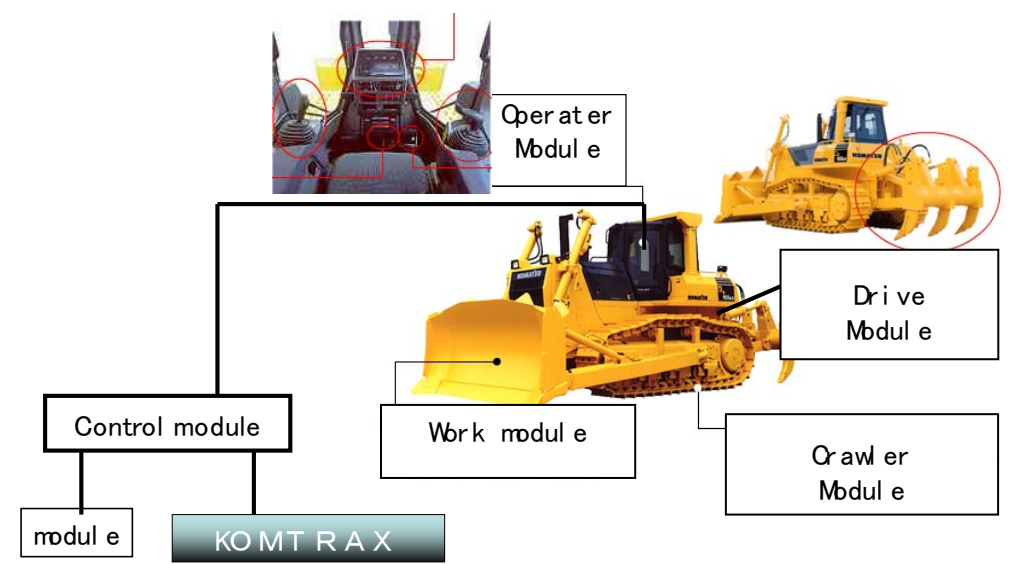

Figure 9. KOMTRX system. Source: Nikkei Business, 2007.

Komatsu-headquarters in Tokyo via the satellite communication. The system Komatsu developed is called "KOMTRAX" system. They started its operation in 2001

Having developed Komtrax, Komatsu is able to enhance its customer service drastically by providing customers with the timely exchange and the repair of parts and also with the theft prevention. Generally speaking, the running cost of construction machinery is three times as high as the purchase cost. The elimination of the wasted activities and the out-of-order situations made possible by using the operation data collected by Komtrax, therefore, is very advantageous to customers. The sales agents located around the world can also benefit by reducing their inventory.

By establishing the Komtrax system, Komatsu headquarters has obtained access to all the data about the operation conditions of all the Komatsu machines installed all over the world. In fact, these collected data are effectively utilized for the discussion on demand forecasting being conducted at the headquarters. Based on those demand estimates, the headquarters formulates production schedules and equipment investment plans at each factory. In 2004, for example, Chinese economy was in downturn, due to the financial policy then implemented by the government. The collected data by the Komtrax system showed clearly that the operating ratios of their machines were abnormally low in China. Komatsu halted its production three months before the demand reduction was officially announced by a Chinese government agency. This gave Komatsu an enormous advantage over competitors.

In 2016, on the contrary, Komatsu detected that the total operating time of the machines which Komatsu installed in Chia, was up by 12 percent with pluses in the preceding eight months, and Komatsu took actions to increase their production, due to the Chinese government policy to sustain their economic activity after their preceding recessions, and due to local governments' plans of infrastructure building by the use of PPP (public private partnership) methods. If we make a retrospective observation about the development and the sophisticated utilization of Komtrax system, therefore, these case histories can be interpreted 
as a service innovation that arises when an existing service innovation is fused with a new corporate management innovation. And it is clear that a component module of Komtrax has evolved into an entire corporate system management.

By the use of AI technologies, meanwhile, Komatsu started providing a service to improve the efficiency of all the jobs conducted on site where a construction is being conducted. When a delay in execution schedule occurs due to a weather change, their service provides site managers with a most efficient plan to reduce the total time of construction based on past data. The information can be received at a tablet owned by site managers. From 2015 on, Komatsu started providing a service called as "smart construction," in which a drone will take 3D pictures of construction sites and their construction machinery will perform necessary operations in a semi-automatic way. It attempts to automate not only a machine operation but also a construction planing. Komatsu is going to spend the 15 to 20 percent of their R \& D budget on their development of next generation technologies. In this context, Komatsu is now collaborating with such institutions like Tokyo Institute of Technology and MIT as well as conducting a joint research with several joint ventures in Japan (Nikkei, 2017/2/16).

Together with NTT DOCOMO Corporation, Komatsu started a computer cloud service called LANDLOG for construction business companies. For the operation of LANSLOG, Komatsu established a subsidiary company, with the joint investments by SAP of Germany and by OPTiM Corporation of software service. This subsidiary company will provide their customers with services involving the use of ICT-mounted shovel loaders, in addition to their various services being provided by its own computer cloud service called Kom connect (Nikkei, 2017/10/16).

By a successful modularization of all the operations involved in construction industry, Komatsu has now their clear vision of the next-generation construction, and is in a process of establishing an IoT platform for construction businesses.

\subsection{Emerging Pattern of IoT System Design}

When it comes to the innovation process of IoT evolution, as described above, it is gradual, incremental, and, most importantly, it is essentially additive, i.e. the value is added continuously. The IoT innovations, therefore, are not based on conventional "creative destruction," but on "creative accumulation" [8]. In short, "accumulation" is a most valuable asset for future IoT system designers.

In his attempt to establish an economic model of the Japanese company and to provide a unified treatment of various features of Japanese practices, Masahiko Aoki compared the informational structures used by various Japanese companies in coordinating operational decisions among interrelated shops, with those used by Western companies [9]. He argues that an important internal characteristic of Japanese firms is horizontal coordination between operating units based on knowledge sharing rather than skill specialization. This is in contrast to the more familiar Western mechanism of hierarchical coordination, 
which is characterized by the separation of planning and implementation and by an emphasis on the economies of specialization.

Aoki once argued that the hierarchical mode may be superior in achieving the organization's goal in either stable or extremely volatile planing environments. In intermediate situation, however, where external environments are continuously changing but not drastically, the horizontal mode is superior. If we extend his argument into the innovation process of IoT evolution described above, we can argue that the Japanese competitiveness might revive again. We will discuss this issue in the next section.

\section{The Japanese Competitiveness in IoT Module Supplying}

In the last section, I argued that an IoT innovation might be favoring some Japanese companies. We illustrated this issue in terms of IoT system integrators. In this section, we will discuss it in terms of IoT module suppliers. We argued that an optimal partitioning of a NC machine tool system based on the digitalization had brought about an IoT evolution via the development of PC-NC machine tools. Therefore, first of all, we have to ask what kind of partitioning will emerge in a future IoT system.

The Internet of Things allows objects to be sensed and/or controlled remotely across the existing network infrastructure, creating opportunities for a more direct integration of the physical world into computer-based systems, and resulting in the improved efficiency, accuracy and economic benefit. When the IoT is augmented with the sensors and the actuators, therefore, the technology becomes an instance of the more general class of cyber-physical systems, which also encompasses technologies such as smart grids, smart homes, intelligent transportation and smart cities ${ }^{10}$.

In our study of automobiles, we hypothesized: the technological base for the digitalization of automobile's control systems lies in the three modules: a sensor, an actuator, and an electronic control unit (ECU) that is inserted between sensors and actuators. In what follows, therefore, I will focus on three kinds of technology: sensing and actuator technologies, as well as an artificial intelligence (AI) technology as representing a case of the ECU component. I will review whether there is any evidence of the Japanese competitiveness in these three module suppliers.

\subsection{Mobile Emission Sensors: A Study of Horiba Co}

In 2015, Volkswagen AG had admitted the years of their cheatings on emissions tests. The VW story of using the defeat device is well documented [10]. However, it is less documented that Horiba, Ltd., a Japanese manufacturer that makes about 80 percent of the world's auto emissions testing system, played a key role in breaking a scandal involving Volkswagen (Bloomberg, 2015/10/2) ${ }^{11}$.

\footnotetext{
${ }^{10} \mathrm{http}: / /$ www.itu.int/ITU-T/recommendations/rec.aspx?rec=y.2060

${ }^{11}$ Bloomberg, Oct. 2, 2015: "Mighty VW was undone by Japanese firm Horiba's portable emissions-gauging systems”.
} 
In 1945, Horiba was established by Masao Horiba with a goal of continuing the nuclear physics research that had been disrupted by World War II. During the Japan's 1960s postwar economic boom, however, Horiba diversified and completed its first emissions analyzer. Its entry into the market was in their response to growing unease about the air pollution. In 1998, Horiba began developing its first portable, onboard emissions analyzer. The first-generation model was a commercial failure. Horiba sent their engineer to the U.S. to learn about its market during 2006-2008. Then, how did Horiba become a detector of the Volkswagen's fraud? In fact, U.S. researchers relied on Horiba's portable emissions measuring systems in a multi-year round of testing that ended up catching Volkswagen in a fake about their engines it had portrayed as "clean" diesels. The Horiba's equipment helped inform the researchers about a scheme in which Volkswagen group cars around the world polluted more on the road than in lab tests, exceeding the U.S. limit by as much as 40 times higher than the law allows. Horiba has all the Japanese carmakers as their customers and also sells their equipment to U.S. and European automakers, suppliers and regulators worldwide. Competitors include AVL List GmbH in Austria, which does far more business with Volkswagen.

While expansion in demand for emissions analyzers, especially mobile ones, will be significant, Horiba has already built a dominant status in this industry. Through their merger and acquisition ( $M \& A$ ), Horiba has become a dominant player in the mobile emission analyzer. In 2005, Horiba acquired a German company Schenck Development Test Systems (including Schenck Pegasus), expanding the automotive market product range to cover the engine and driveline testing tools, including brake testing and wind-tunnel balances. Furthermore, Horiba acquired the Interautomation Group of Ontario, Canada, with its real-time preemptive kernel Linux-based ADACS data acquisition and control software suite. In 2015, Horiba acquired a 70-years-old British MIRA Ltd., which was inaugurated by the government's research establishment called "Motor Industry Research Association.” Expecting the synergy of Horiba's existing technologies with those owned by MIRA, Horiba is now expanding their business into engineering areas. In Europe, indeed, the new regulation which enforces the measurement of running gas emission, called RDE (Real Driving Emissions), is to be legislated in the coming September of $2017 .^{12}$

Horiba is now expanding their businesses into the areas related to self-driving of automobiles. The performance of the sensor is critical to a stable running by self-driving. Horiba is now going to utilize their know-how on sensor technologies and to expand their businesses of providing car manufactures with their self-driving tests. For the tests of self-driving, Horiba is going to use the testing facilities owned by the British MIRA acquired by Horiba in 2005. They are going to provide car manufactures with a system in which the car-mounted camera will detect the pedestrian and the signpost, and which thereby will control the

${ }^{12}$ http://www.horiba.com/uploads/media/HORIBA_2015AR_jp_HQ.pdf 
speed according to the limits displayed in the signpost. The commission Horiba received through this provision business of self-driving did amount to as much as seven billion yen (Nikkei, 2017/6/17).

The Horiba group now consists of about 42 companies, spread over about 15 countries. In the past, Japanese companies did rarely choose the $\mathrm{M} \& \mathrm{~A}$ as a method of their diversification [11]. Based on this analysis of Horiba's development trajectory, however, we might be able to hypothesize that M \& A is an effective method, in which a component supplier in the existing system configuration can grow up to a critical module supplier for the future IoT system integrators.

\subsection{Versatility of the Spindle Motor: A Study of Nidec Corporation}

The effectiveness of $\mathrm{M} \& \mathrm{~A}$ as a method for the IoT evolution can be tested further by examining another important component for the IoT system, i.e., actuator. Nidec Corporation is a Japanese manufacturer of electric motors. Their products are used in hard-disk drives, electric appliances, automobiles and commercial and manufacturing equipment. The company has the largest global market share for tiny spindle motor that power hard-disk drives. Two product groups with the largest sales are hard-disk drive motors, and electrical and optical components, with $21.5 \%$ and $30 \%$ of their sales respectively. As of 2015 , the company has 230 subsidiary companies located across Japan, Asia, Europe, and American continents. The company obtained the 42th position on the 2005 edition of Business week Infotech 100 list. Also the Nidec was featured on the 2014 Forbes World's Most Innovative Companies list (Nikkei Business, 2016/10/24).

The uniqueness of Nidec Corp lies in how they grew so rapidly, starting from a spindle motor of audio-devices to hard-disk drives for PC, and now expanding their businesses into automobiles, by supplying every kind of the actuator in every part of an automobile (Nikkei, 2017/12/5). Nidec has accomplished this by a successful and skillful series of M \& A. It was founded in Kyoto in 1973 with only 4 employees. After working for an audio maker, Shigenobu Nagamori founded Nidec at the age of twenty-eight, setting their objectives as a non-family company, not being a sub-supplier, but becoming a world enterprise. However, their company remained as one of the small motor suppliers. The first opportunity of growth came in the mid-1980s, when the PC market suddenly and drastically expanded. Nidec developed a precision motor for the hard-disk drives which responded better to customers' needs, and became one of the top producers of the precision motor.

The second opportunity arrived in the mid-1980s. They started M \& A, aiming at leading the innovation of precision motors, by acquiring several companies such as Shimpo manufacturing in 1995, Tosok Co. in 1997, and Sankyo-seiki Co. in 2005. In other words, they grew so fast up to the annual sales of 485.5 billion yen by acquiring those domestic companies. The third opportunity came for expanding their business of the precision motor into other areas including cars and home appliances. It became possible by the acquisition of overseas companies, starting from acquiring a business unit of motor/actuator from 
Valeo Co., a French car motor company, in 2006, and other acquisitions of overseas companies followed. By these acquisitions, they entered new markets including cars, home appliances, and industrial and commercial products. As of 2015 , the total sales has risen over one trillion yen and the export ratio is over 80 present. This rapid growth was possible by having acquired a total of 49 companies during 33 years, as shown in Table 2.

Table 2. Chronology of M \& As by Nidec.

\begin{tabular}{|c|c|c|c|}
\hline Time & Names of Companies & Business Area & Country \\
\hline 2003 & Sankyo-seiki & & \\
\hline \multirow[t]{3}{*}{2006} & Fujisoku & & \\
\hline & Valeo & Motor \& Actuator & France \\
\hline & Brilliant & & Singapore \\
\hline 2007 & Nippon Servo & & \\
\hline \multirow[t]{2}{*}{2009} & $\mathrm{ACC}$ & Motor for appliance & Italy \\
\hline & SCWADO & & Thailand \\
\hline 2010 & Emerson Electronics & Motor; Control devises & USA \\
\hline 2011 & Sanyo-seimitsu & & \\
\hline \multirow[t]{6}{*}{2012} & The Minster Machine & & USA \\
\hline & Ansaldo Sistemi Industriali & & Italy \\
\hline & Avtron Industrial Assoc. & & USA \\
\hline & SCD & & Korea \\
\hline & Kinetek group & & USA \\
\hline & Kaiyu Auto Electric (Jiangsu) Co. Ltd. & & China \\
\hline \multirow[t]{2}{*}{2013} & Mitsubishi Materials MC & & \\
\hline & Honda Elecsys & & \\
\hline 2014 & Geraete-und-Pumpenbau & & Germany \\
\hline \multirow[t]{6}{*}{2015} & Montortecnia & & Italy \\
\hline & Chia Tex Mechanical \& Electrical & SR motor-drive & China \\
\hline & Arisa & & Spain \\
\hline & KB Electronics & & USA \\
\hline & EMG Electromeccanica & & Italy \\
\hline & Nagata Opto Indonesia & & Indonesia \\
\hline \multirow[t]{4}{*}{2016} & E.C.E. & & Italy \\
\hline & ANA IMEP & & Rumania \\
\hline & Emerson Electronics & Motor-drive & \\
\hline & & Electric power generator & USA \\
\hline
\end{tabular}

Source: Compiled by the author from Nikkei Business, 2016/10/24. 
All the M \& As' have generated synergies by combining Nidec's competences with those that were owned by the acquired companies. And these synergies made possible for Nidec to enter into new businesses such as car-related products. And this M \& As' brought Nidec a drastic change in their portfolio from 2005 to 2015, as seen in Table 3. As seen in the table, a share of precision motors was $51 \%$ of the total company's sales in 2005 , but it was slightly reduced to $38 \%$ in 2015. On the other hand, a share of motors used for commerce and industrial companies including car and home appliance manufacturers was only $7 \%$ in 2005, but became the largest segment of the Nidec's total sales (47.1\%) in 2015.

Quite recently, in December 4th of 2017, Nidec announced to establish in May of 2018 a joint venture company with a French PSA (Peugeot Citroën) group in developing a low-cost and high efficient motor for driving the EV (electric vehicles), and in delivering their products mainly to PSA as well as other car manufacturers. Although Nidec has already kept a dominant position in providing motors for the power-steering and for the breaking, supplying of motors for the main driving is the first experience to Nidec. Nidec will take a CEO position in these joint efforts, and its business will grow to the $40 \%$ of their total sales (Nikkei 2017/12/4). In summary, we can confirm the hypothesis concerning the effectiveness of M \& A mentioned in our study of the sensor technology, is also valid in the actuator technology.

\subsection{Commercialization of Embryonic AI: A Study of Japanese Word Processor}

For a discussion of the future IoT innovation, we cannot dismiss the suppliers of software such as AI (Artificial Intelligence) and Big Data, However, it is too premature to identify definitely which industry and which country is going to lead software technologies in IoT innovation. This is especially true in Japan. We do not know yet whether any Japanese company can be a critical player in this field.

According to Murakami ${ }^{13}$ (Nikkei 2016/0910), we are in the third boom of AI research following the first one in 1950-1960 and the second one in 1980s. He argues that what is unique about the third one is that we are in a midst of

Table 3. The shift in Nisdec's business portfolio from 2005 to 2015.

\begin{tabular}{ccc}
\hline Business area & 2005 & 2015 \\
\hline Small precision motor & $51.0 \%$ & $38.0 \%$ \\
Mounted in cars and others & 7.0 & 47.1 \\
Equipment & 13.6 & 9.0 \\
Electronics and Optics parts & 24.0 & 9.0 \\
Miscellaneous & 4.3 & 0.4
\end{tabular}

Source: Compiled by the author from Nikkei Business, 2016/10/24.

${ }^{13}$ Murakami, N.: "Japan can be a member of the AI related advanced nations." He was a vice president of Google Inc. and a president of Google Japan in 2003-2008. 
commercialization stage of AI research. Because of their unique cultural backgrounds, i.e. the Japanese language, she had to go through an embryonic version of commercializing a kind of AI technologies in processing their complex and complicated structure of the language. AI research is defined as a study of "intelligent agents": any device that perceives its environment and takes actions that maximize its chance of success at some goal. Other definitions also include learning as additional criteria [12].

In 1975, Toshiba introduced the first Japanese language word processor, JW-10, into market. This achievement was later designated as one of the IEEE Milestones in Electrical Engineering and Computing, and awarded by the Honda prize in Japan. The Japanese language uses a mixture of the 50-character kana alphabet and over 3000 Chinese kanji characters. The keyboard of a traditional Japanese typewriter-actually a plate printed with rows of tiny characters and a mechanical arm with a pointer to select them-contains more than 3000 characters that the operator must find and punch in one by one. Not surprisingly, only trained specialists are able to operate Japanese typewriters. Thus, the diffusion of Japanese typewriters was far behind that of the American and European machines, and it was feared that this would limit office automation in Japan.

The first attempt at a Japanese-language word processor, which also used a plate printed with individual characters, ended in failure. Manufacturers were forced to return to fundamental research, starting with the basic principles of linguistics. After ten years of wide-ranging research at Toshiba's laboratories, a new method was devised in which kana letters could be converted to kanji characters. Working from a keyboard of 48 kana letters, an operator can simply key in text as it is pronounced, while a computer, programmed with a dictionary of Japanese vocabulary and grammar, automatically converts the letters into kanji characters where necessary [1].

According to Murakami, a key technology in the third AI boom is "self-learning," and the idea of deep-learning will consist a breakthrough in AI technologies. Although it was far from a deep-learning, a provision of learning function with the Japanese word processor was vital in its success. In the Japanese grammar, key concepts in a sentence are written in a combination of more than two different kanji characters. And different combinations of kanji letters are often pronounced the same phonetically, i.e. the same combination of kana letters. In choosing a specific combination of kanji letters, the machine has to learn a most appropriate combination of kanji characters among candidates whose pronunciation are the same. This selection can be improved through the learning about the writer's behavior of using a specific combination of kanji letters on the basis of the writer's past record of writing sentences.

In the seven years since the development of Japanese-language word processors, the price has been reduced by 98 percent and their size has been significantly reduced. Thus, they are now widely used in offices and in homes. Although this kind of learning in the Japanese word processor was at an embryonic stage of AI development, these experiences in mechanizing the Japanese word 
processing will be some help in developing the advanced AI technologies with big data, i.e. a core part of the future IoT revolution. It is definitely helpful in commercializing the AI technologies.

\section{Cautious Management Styles for IoT Revolution}

In the 1970s and 1980s, the Japanese firms triggered a global revolution in operational effectiveness. However, Michael Porter [2] argues that operational effectiveness is not strategy. Competitive strategy is about being different. In this context, he also described: Japanese companies rarely developed distinct strategic positions; most Japanese companies imitate and emulate one another, thus, driving themselves toward competitive convergence. However, he noted that Sony, Canon, arid Sega were the exception rather than the rule.

When it comes to the innovation process of IoT evolution, as described above, it is gradual, incremental, and value-additive. Those Japanese companies which we studied in this paper are utilizing their core competences accumulated in their original businesses, to manage different trajectories of their business diversification and/or of their whole company's morphing. Their innovations are not based on conventional "creative destruction," but on "creative accumulation." [8]. In short, "accumulation" is a most valuable asset of some Japanese companies for surviving in radically changing technology and market environments.

In their strategic positionings, being different has never been the purpose of Japanese companies, but it is the positioning about how to accumulate selective technologies in a creative way. Since the process of IoT evolution is characterized as incremental and additive, a cautious positioning rather than that of being different is an important strategy in IoT revolution. In this section, I will illustrate this concept of cautious strategic positioning in terms of management of business integration in international $\mathrm{M} \& \mathrm{~A}$, manufacturer's strategy of incorporating service/downstream offerings [13], and R \& D strategy of securing a technological independence from a dominant component supplier. And at the end of this section, we are going to suggest our tentative perspectives on the IoT revolution in contrast to those of IT revolution.

\subsection{Management of International M \& A: A Case of DMG-Mori Seiki Co}

Generally speaking, a cautious stance in strategic positioning is conspicuous when Japanese companies extend their business into the global landscape. This implies that priority is placed on business integration rather than on the termination of unprofitable parts of business.

In May 2015, M \& A between Japanese Mori Seiki Co. and German DMG Co. (Gildenmeister Aktien Gesellschaft), was formally announced. Mori Seiki (the $5^{\text {th }}$ world largest machine tool company as of February in 2014), acquired 52.4\% of the stock of DMG (the $2^{\text {nd }}$ largest). While DMG was established in 1870 and its total sales were 289.8 billion Japanese yen in 2014, Mori Seiki was established 
only in 1948 and its total sales were 117.8 billion yen $^{14}$. It is, indeed, reported in Germany that a "mouse" did swallow a "cat" (Nikkei Business, 2015/5/25). Thus, DMG-MORI SEIKI Co. became the largest company in the machine tool manufacturing, by surpassing then No.1 Chinese Company. Mori Seiki spent as long as 6 years to complete this merger. In most cases of $\mathrm{M} \& \mathrm{~A}$, priority is often placed on the termination of unprofitable businesses and reduction of the number of employees, rather than on business integration such as joint product development and the sharing of distribution channels. For this purpose, two specific methods were employed, which are almost opposite to the conventional wisdom on $\mathrm{M} \& \mathrm{~A}$. The first is to "double staffing in management," namely, two managers from each company are assigned for a same management position, because they thought, German system is better in procedures and rule-making for systems integration, while Japanese system is stronger in production scheduling and operation strategy.

The second is that enough time and budget was allocated to make possible good communication between the employees of the two companies. Their basic philosophies on the design were different from each other. DMG's lathe uses more common parts, and thus costs less than MORI's machine, while MORI tries to accommodate every detail of the customers' demands, thus uses less common parts even in situation where cost reduction is possible. Meanwhile, they came to a common understanding: there is no difference in accommodating customers' requirements, but customers' demands in Germany and Japan are indeed different from each other. In short, M \& A will not work properly unless two parties know each other well.

\subsection{Downstream into Service Innovation: A Case of Komatsu Co}

It is widely argued that a competitive manufacturing strategy may consider the going-downstream business models, owing to the abundant knowledge of products and markets owned by manufactures [14]. It is not easy to implement it; at least we need a technology to make it possible.

The development of Komtrax system, indeed, was not as straightforward as we can imagine. In the mid-1990s, the country's investment in construction businesses fell down significantly. Facing this reduced investment, companies had to revise ways in which machineries was procured. This meant a shift away from the ownership to the leasing and rental (21\% of machinery was either leased or rented by $1993,30 \%$ by 1997 , and $40 \%$ by 2006). In 1997, Masahiro Sakane (later became CEO of Komatsu Co. in 2001) was appointed as the director of the business planning and administration office. At the time, this office was staffed by people dispatched from various divisions. At the end of 1997, the office received a business plan of 10 pages long, from those engineers dispatched from the development department. This plan was for a business model for remotely monitoring the machinery, which was in effect the prototype of the

${ }^{14}$ Nikkei Business (2015/5/25): “Company Study on DMG-MORI SEIKI,” Volume 49. 
Komtrax system.

Having spent a long time in the service department, Mr. Sakane had a deep appreciation of the intricacies of managing construction machinery maintenance, and hence understood well the value and potential of the Komtrax system (Nikkei, 2014/11/24), and thus this idea proceeded into the development stage. In this regard, the Komtrax development was initiated as a kind of a local project using funds provided by the business planning and administration office. The company completed the 5 prototypes by 1998, and asked Chikashi Shike of "Big Rental" (a rental company at Koriyama in Fukushima prefecture), which had only started up in 1997, to test the 5 prototypes. At that time, Mr. Shike was also thinking about a brand-new rental business model that entailed using IT for centralized management to raise the utilization rates of rental construction machinery. He agreed to take on the prototypes for testing because this remote construction machinery monitoring system fit well with his idea. Being engaged in a rental business, he had no difficulties in understanding the inherent value of the Komtrax system ${ }^{15}$.

At the end of 1998, it was suggested at Komatsu that fifty pieces of the prototypes should be subsequently tested. However at a development meeting, supervising executives took a negative view regarding the continued testing. At that meeting, meanwhile, Mr. Shike was asked for his opinions about the commercial advantages of developing a remote monitoring system. Shike explained that the system was a piece of remote communications infrastructure, and thus it was not an appropriate timing to discuss in details what sorts of businesses would be enabled by it. ${ }^{16}$ Unfortunately though, it was decided that the remote monitoring system development should be cancelled at Komatsu. The Komatsu development team could not paint a picture of a business model using the Komtrax, because they did not have an understanding of its inherent value.

Nevertheless, Mr. Shike, who understood the value of Komtrax, soon wrote an order for 1000 units and paid Komatsu 150 million Japanese yen (JPY) -an order made despite of Big Rental's having only 500 pieces of rental construction machinery at the time. In those days, the Komtrax units were externally attached and cost 150,000 JPY per unit. Thus, such a large order enabled the Komtrax to sustain this viable business, and so the development was continued within Komatsu. In the beginning of 2000, the Big Rental grew rapidly and within 3 years became the top rental company in the Fukushima prefecture. Shike quickly refitted all the Big Rental's construction machinery with the Komtrax units as soon as the units arrived from Komatsu. The product originally consisted of a communications terminal and modem, GPS and a simple CPU, etc.

The capabilities and advantages of the Komtrax in a remote management of machinery in construction sites, became widely known gradually. Komatsu Co.,

\footnotetext{
${ }^{15}$ It is based on the interview with Mr. Shike, conducted by the coauthor of this paper, Shibata, T. in December 2014.

${ }^{16} \mathrm{We}$ are told that Mr. Shike responded by saying that Alexander Graham Bell had not clearly understood what kinds of businesses would be brought about with the development of the telephone.
} 
meanwhile, filed a business model patent for rental businesses so that the Komtrax could be used in the rental business. At that time, the Komtrax was known as a business model for rental businesses, and was only available as a user option. In June 2001, Mr. Sakane became the CEO of Komatsu company. He had aggressively pursued the possibility of utilizing the Komtrax, not only as a tool for customer services, but also as a tool for visualizing corporate management [15]. Mr. Shike, meanwhile, was recruited to Komatsu Co. as an executive officer in 2014.

\subsection{R \& D for Securing Independence from Dominant Supplier: A Case of Nidec Corp}

M \& A is a quick way of absorbing necessary technologies, but it is sometimes dangerous for being over-dependent on outsourcing of the critical technologies. It does not give any incentives for the advanced development of future businesses. What kind of indigenous R \& D activities were conducted by Nidec Corporation for themselves, which made possible such a drastic growth in such a short time horizon?

It is an $\mathrm{R} \& \mathrm{D}$ targeted towards making possible technological independence from a dominant component supplier in the midst of a rapid $M \& A$. I will illustrate a typical example of this kind of R \& D activity. It was about bearing technology in the hard disk devices (HDD). The dominant-design of bearing in hard disk drives used to be that of ball bearings. Ordinary ball bearings, however, would have a short life or cause high noise and vibration. FDBs (fluid dynamic bearings) for the hard disk drive motor, on the other hand, are both quieter and cheaper than the ball bearings they replace, because the shaft is supported by oil and dynamic pressure slots instead of balls, as shown figuratively in Figure 10.

The most important performance criterion for the HDD is, of course, a capacity for the memory. As the capacity gets larger and larger, the requirement for the motor gets also demanding. Engineers at Nidec became aware that the requirement would be soon beyond the natural evolution of ball bearing technologies. At Nidec, therefore, while they were trying to improve their product on the basis of ball bearings technology, they also established an R \& D center of

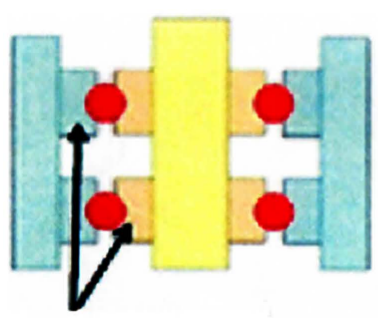

ball bearing

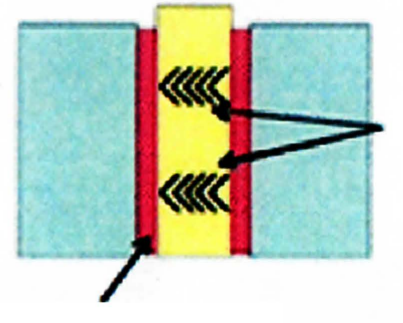

lubrication oil

dynamic pressure slot

Figure 10. Comparison between ball bearing and fluid dynamic bearing. Source: Okayama, Y. (2012): “Technology management in a transition of HDD motors," Term Paper at Business School of Kwansei University. 
fluid dynamic bearings ${ }^{17}$, which is located physically and organizationally far from the $\mathrm{R} \& \mathrm{D}$ center for ball bearings.

We might be able to formulate this Nidec's management scheme described above in a much broader context [16]: what is the effective management scheme for the company which has to face with the dilemma of either switching to a new technology or sticking with the tried-and-true old technology? This scheme of concurrent pursuit of the alternative options, indeed, was already used intensively by Fanuc Corporation, a world largest numerical controller module provider for machine tools. In 1970s, Fanuchad to confront the major shifts both in economic and in technological landscape. In other words, Fanuc had to undergo two major transitions [17] [18]. The first transition involved servomotor architecture entailing a major change from an open-loop architecture to a closed-loop architecture. The second technology shift involved the NC logic unit architecture from hard-wired NC logic to a soft-wired NC logic based on MPU (micro-processor unit). Fanuc had overcome these two transitions successfully by the use of the scheme of concurrent pursuit of the two options.

Anyway, the successful development of FDBs at Nidec made it possible in a few years to delete all the ball bearings which had been the dominant-design in the past 20 years since the HDD was invented. This technology development put Nidec in a positon of 78 percent of the market share in the motor for the HDD. While HDD manufactures have been concentrated in four companies: Western Digital (USA), Seagate (USA), HGST (Japan), and Toshiba (Japan), HDD motor manufacturers have been concentrated in four producers: Nidec (Japan), NMB (Nippon Miniature Bearing, Japan), JVC (Japan Victor Co., Japan), and SEMCO (Samsung Electro-Mechanics, Korea). While at the product level of the HDD, the $85 \%$ market share is owned by Seagate and Western Digital, at the component level of the motor, Nidec alone occupies $78 \%$ of the world market.

\section{Perspectives on the IoT/IT Innovation}

On the basis of these cases described above, we observe that many Japanese component module suppliers and system assemblers are upgrading their individual systems to an advanced level, i.e. towards an IoT system. By analyzing the experiences of the Japanese companies, therefore, we attempt to develop a new perspective within which individual ITs and progressive physical technologies are built into a larger system and thus integrated into the social systems of a higher degree, i.e. a perspective on IoT (Internet of Things) evolution, in contrast with that for IT (Information Technology) revolution. According to Yoffie [19], who studied the phenomenon of "convergence" in the context of IT revolu-

\footnotetext{
${ }^{17}$ Fluid Dynamic Bearing (FDB) inserts the fluid substance (oil) to maintain the separation between the bearing races. The dynamic fluid pressure which occurs during rotation is used to sustain the spindle's rotating. Compared to the ball-bearing, this mechanism makes possible not only higher anti-shock but also the smaller aptitude of vibration. It enhances the precision of rotation, thus, upgrades the memory capacity of HDD. Since here is no physical contact, it is quieter, and the further miniaturization becomes available easily.
} 
tion, many companies see digital convergence delivering Joseph Schumpeter's promise of "creative destruction," and have been seeking the great new idea or grand combination that can be used to create a new digital era, sweeping away the existing order. Indeed, as is well known, Joseph A. Schumpeter in 1926, described:

Technologically as well as economically considered, to produce means to combine the things and forces within our reach. Every method of production signifies some such definite combination. In so far as the new combinations appears discontinuously, then the phenomenon characterizing development emerges [20].

In fact, Yoffie argues: the lessons of the computer revolution are that many of the greatest commercial successes were creative combinations of available technologies with new models of doing business. And he concluded: success in this new world is most likely to be fueled by companies that exploit "creative combinations" of old and new technologies. Therefore, we can say that what happened in the IT revolution confirms the Schumpeterian argument, rather than denying it.

As our case studies demonstrated clearly, IoT innovation is accomplished by connecting individual components by the network with sophisticated software. Moreover, we can generalize: IoT innovation is not attained by economy of scale, nor by the economy of scope, but only by the economy of connectivity, if any. We would argue, therefore, the combination of the things in Schumpeter should be replaced by the (network) connectivity in the IoT economy.

In a relation to the concept of creative combination, Yoffie also noted: we cannot lose sight of Schumpeter's equally important insight that prior to creative destruction, entrepreneurs who have created no original means of production, will flourish by "carrying out" new combinations that take existing approaches and use them "more appropriately, more advantageously." In order for new combinations to be carried out successfully, indeed, Schumpeter argued:

We never assume the carrying of new combination takes place by employing means of production which happen to be unused. As a rule the new combinations must draw the necessary means of production from some old combinations. (Schumpeter, 1926, 1983)

In converging technologies, Yoffie concluded: firms are required to master a far broader array of technologies and markets, which often extend beyond their sphere of competence. One solution is to build broad-based alliance networks that try to leverage the competencies of others.

Our interpretation of this Schumpeter's important insight in the IoT contexts, meanwhile, differs a little bit from that of Yoffie in the IT context. Harvard Business School Scholars, Baldwin and Clark [4], in this context, tried to use the computer as the powerful lens through which to observe and study the evolution of designs, and the development of an industry. They found out strikingly: the 
changes that can be imagined in a modular structure are spanned only by six, relatively simple modular operators. These operators can generate all the possible evolutionary paths for the structure. The six modular operators are: splitting, substituting, augmenting, excluding, inverting, and porting. The "porting" operator, as the name suggests, ports the modules to other systems. The other five operators only work within their respective system. Porting occurs when a hidden module "breaks loose"18 and is able to function (via translation) ${ }^{19}$ in more than one system, under different sets of design rules ${ }^{20}$, i.e., a different architecture.

Based on the concept of a "porting operator," we can interpret that the IoT evolution in the machine tool industry have been realized through the two-stage process of porting: in the first stage, the PC module is ported into the NC system and, and, in the second stage, the Internet module is ported into the PC-NC system, as depicted in Figure 11. Thus, a new manufacturing architecture is emerging whereby different factories are interconnected with each other. As indicated by this example, we argue, that "drawing the necessary means of production from some old combinations" in Schumpeter, should be replaced by "porting of a hidden module so that it can function under a different architecture" in the IoT economy.

By referencing the monumental work by Schumpeter, we have argued that the IoT revolution combined with the development of digital economy is truly bringing about a fundamental change in technology development. Therefore, we can summarize the comparative difference in perspectives on innovation among: Schumpeter on modern technologies; Yoffie on IT revolution; and our findings on IoT evolution, as shown in Table 4.

Table 4. Comparison of perspectives on innovation.

\begin{tabular}{|c|c|c|c|}
\hline & $\begin{array}{l}\text { Modern Technology } \\
\text { Joseph Schumpeter }\end{array}$ & $\begin{array}{l}\text { IT David } \\
\text { Yoffie }\end{array}$ & $\begin{array}{c}\text { IoT } \\
\text { F. Kodama, et al. }\end{array}$ \\
\hline Concept: & $\begin{array}{c}\text { Creative } \\
\text { Destruction }\end{array}$ & $\begin{array}{c}\text { Creative } \\
\text { Combination }\end{array}$ & $\begin{array}{c}\text { Creative } \\
\text { Connectivity }\end{array}$ \\
\hline Carrying-out: & $\begin{array}{l}\text { Drawing from Some } \\
\text { of old Combinations }\end{array}$ & $\begin{array}{c}\text { Networking } \\
\text { Competencies of } \\
\text { Others }\end{array}$ & $\begin{array}{l}\text { Porting of existing } \\
\text { module to new } \\
\text { architecture }\end{array}$ \\
\hline
\end{tabular}

\footnotetext{
${ }^{18}$ The first step in porting is to modularize a module. However, to make a module portable, designers must first partition its design into: 1) those parts affected by the surrounding system and 2) those not affected. They must then create a "shell" around the parameters not affected. Once the shell exists, the interior parts of the module are doubly hidden: they will not affect the surrounding system, and the system will not affect them. This "two-way invisibility" is potentially advantageous, for not only can these parts of the module be changed without changing the larger system but they can also migrate from one system to another without having to change their own inner structure. Source: Baldwin \& Clark.

${ }^{19}$ If all of these actions-sub-splitting, defining a shell, and designing translator modules-can be accomplished, the ported module will be able to function in two or more otherwise incompatible systems.

${ }^{20}$ If all of these actions-sub-splitting, defining a shell, and designing translator modules-can be accomplished, the ported module will be able to function in two or more otherwise incompatible systems.
} 


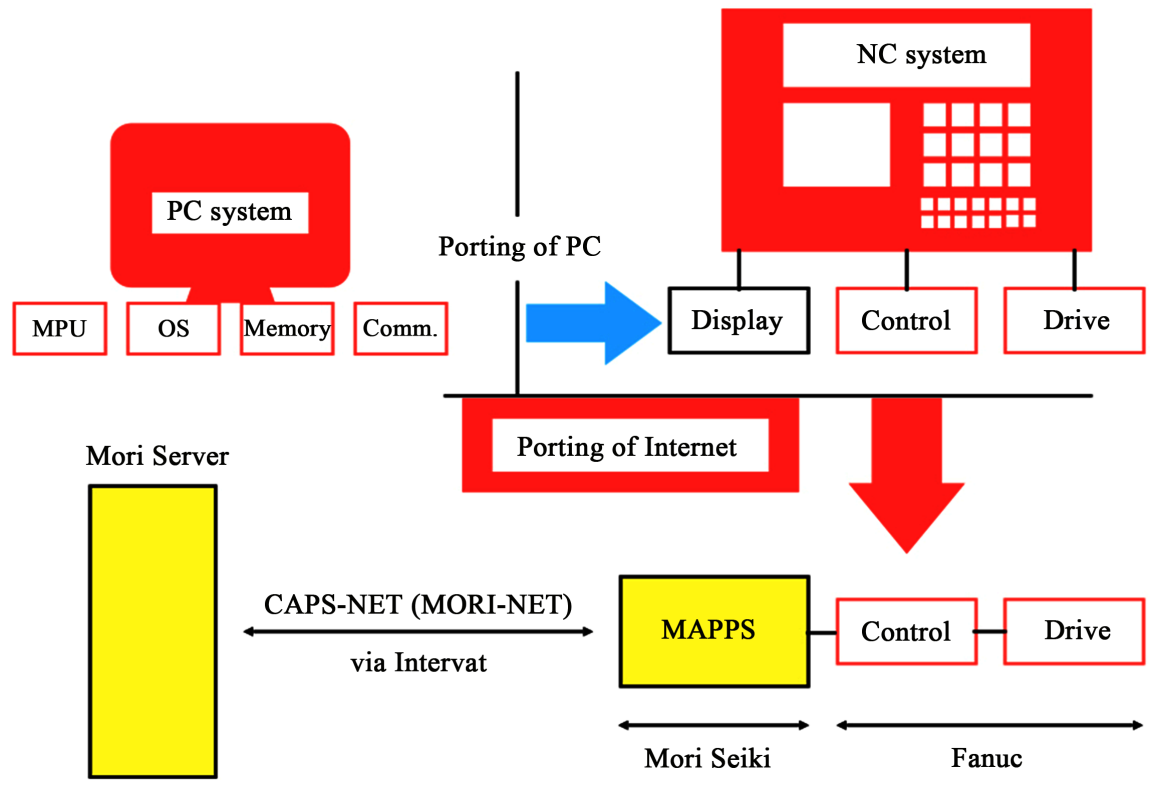

Figure 11. A new manufacturing architecture is emerging though two steps of porting. Source: Shibata [7].

\section{Concluding Remarks}

We will conclude that we should attempt to reformulate innovation in a new light. For example, the IoT innovation occurring in the automobile industry, which we can call "Car Renaissance," serves as a good illustration. As we witness the "true automobile" of today, indeed, we had been wandering along through the "dark ages" of the last 100 years since Ford's innovation. In conclusion, we anticipate the IoT revolution will take us into the highly sophisticated techno-society. Indeed, Techno-Renaissance is dawning upon us; it is almost here and not in the distant future as widely predicted.

\section{References}

[1] Kodama, F. (1995) Emerging Patterns of Innovation. Harvard Business School Press, Boston.

[2] Porter, M. (1996) What Is Strategy? Harvard Business Review.

[3] Grove, A. (1996) Only the Paranoid Survive: How to Exploit the Crisis Points that Challenge Every Company and Career. Doubleday, New York.

[4] Baldwin, C. and Clark, K. (1997) Managing in an Age of Modularity. Harvard Business Review, 84-93.

[5] Kodama, F. (2004) Measuring Emerging Categories of Innovation: Modularity and Business Model. Technological Forecasting \& Social Change, 71, 623-633. https://doi.org/10.1016/S0040-1625(03)00084-2

[6] Clark, K. and Fujimoto, T. (1991) Product Development Performance: Strategy, Organization, and Management in the World Auto Industry. Harvard Business School Press, Boston.

[7] Shibata, T. (2009) Product Innovation through Module Dynamics. Journal of Engineering and Technology Management, 26, 46-56. https://doi.org/10.1016/j.jengtecman.2009.03.004 
[8] Suzuki, J. and Kodama, F. (2004) Technological Diversity of Persistent Innovators in Japan. Research Policy, 33, 531-549. https://doi.org/10.1016/j.respol.2003.10.005

[9] Aoki, M. (1990) Toward an Economic Model of the Japanese Firm. Journal of Economic Literature, 28, 1-27.

[10] Ewing, J. (2017) Faster, Higher, Father: The Inside Story of the Volkswagen Scandal. Penguin Random House, New York.

[11] Kodama, F. (1986) Technological Diversification of Japanese Industry. Science, 233, 253-392. https://doi.org/10.1126/science.233.4761.291

[12] Russell, S. and Norvig, P. (2003) Artificial Intelligence: A Modern Approach, Prentice Hall, New Jersey.

[13] Howells, J. (2004) Innovation, Consumption and Service: Encapsulation and the Combinatorial Role of Services. The Service Industries Journal, 24, 19-36. https://doi.org/10.1080/02642060412331301112

[14] Wise, R. and Baumgartner, P. (1999) Go Downstream: The New Profit Imperative in Manufacturing. Harvard Business Review, 77, 133-141.

[15] Sakane, M. (2006) An Endless Challenge to Supper Management. Nikkagiren Publishing, Tokyo. (In Japanese)

[16] O’Reilly, C. and Tushman, M. (2004) The Ambidextrous Organization. Harvard Business Review, 74-81.

[17] Shibata, T. (2011) Managing the Change of Architecture Knowledge. International Journal of Innovation Management, 15, 1093-1112. https://doi.org/10.1142/S1363919611003623

[18] Kodama, F. and Shibata, T. (2017) Beyond Fusion towards IoT by Way of Open Innovation: An Investigation of the Japanese Machine Tool Industry 1975-2015. Journal of Open Innovation: Technology, Market, and Complexity, 3, 1-19. https://doi.org/10.1186/s40852-017-0073-0

[19] Yoffie, D. (1996) Competing in the Age of Digital Convergence. California Management Review, 38, 31-53.

[20] Schumpeter, J.A. The Theory of Economic Development, by Opie, R., Harvard College, 1934; by Elliott, J.E., Transaction Publishers, New Jersey, 1983; Theorie der wirtschaftlichen Entwiklung (1926). 